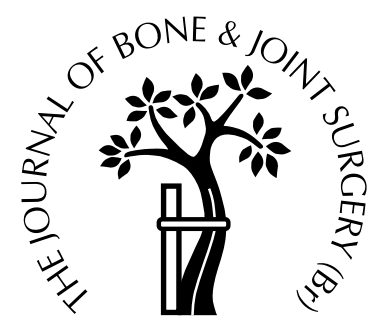

\title{
Screw versus suture fixation of Mitchell's osteotomy
}

\author{
A PROSPECTIVE, RANDOMISED STUDY \\ J. D. F. Calder, J. P. Hollingdale, M. F. Pearse \\ From Imperial College School of Medicine and the Central Middlesex Hospital, \\ London, England
}

W e studied prospectively 30 patients who had a Mitchell's osteotomy secured by either a suture followed by immobilisation in a plaster boot for six weeks, or by a cortical screw with early mobilisation.

The mean time for return to social activities after fixation by a screw was 2.9 weeks and to work 4.9 weeks, which was significantly earlier than those who had stabilisation by a suture (5.7 and 8.7 weeks, respectively; $\mathbf{p}<0.001)$. Use of a screw also produced a higher degree of patient satisfaction at six weeks, and an earlier return to wearing normal footwear. The improvement in forefoot scores was significantly greater after fixation by a screw at six weeks ( $p=0.036)$ and three months $(p=0.024)$. At one year, two screws had been removed because of pain at the site of the screw head.

Internal fixation of Mitchell's osteotomy by a screw allows the safe early mobilisation of patients and reduces the time required for convalescence.

J Bone Joint Surg [Br] 1999;81-B:621-4.

Received 28 October 1998; Accepted after revision 19 January 1999

Mitchell's osteotomy is widely used for the correction of moderate hallux valgus. It was originally described by Hawkins, Mitchell and Hedrick ${ }^{1}$ who used a suture to secure the osteotomy. Mitchell et $\mathrm{al}^{2}$ recognised that for an acceptable anatomical result the osteotomy must be stable, and dorsal displacement must be prevented to avoid secondary metatarsalgia. They recommended that it should be protected with tongue depressors for the first ten days after operation, followed by a below-knee walking cast for six to eight weeks.

J. D. F. Calder, FRCS, Specialist Orthopaedic Registrar

J. P. Hollingdale, FRCS, Consultant Orthopaedic Surgeon

Department of Orthopaedics, Central Middlesex Hospital, Acton Lane, Park Royal, London NW10 7NS, UK.

M. F. Pearse, FRCS (Orth), Senior Lecturer and Honorary Consultant Orthopaedic Surgeon

Imperial College School of Medicine, Charing Cross Hospital, Fulham Palace Road, London W6 8RF, UK.

Correspondence should be sent to Mr J. D. F. Calder at the Princess Royal Hospital, Lewes Road, Haywards Heath, West Sussex RH16 4EX, UK.

(C)1999 British Editorial Society of Bone and Joint Surgery

0301-620X/99/49595\$2.00

VOL. 81-B, No. 4, JULY 1999
The use of night splints for a further 12 weeks to avoid pressure on the toes from the bedclothes was also suggested.

This prolonged period of immobilisation is unacceptable for such a common procedure. A recent biomechanical study has shown that fixation of Mitchell's osteotomy by a screw is four times stronger and 12 times more stable than that with a suture. ${ }^{3}$ Using piezoelectric studies to investigate the shear forces acting across the metatarsal during walking, it was calculated that fixation by a screw would be strong enough to allow early weight-bearing across the osteotomy, removing the need for cumbersome splintage and immobilisation.

We have investigated whether use of a screw would allow early mobilisation and a more rapid return to the activities of daily living compared with fixation by a suture.

\section{Patients and Methods}

After approval by the local Ethical Committee, we divided 30 patients with symptomatic hallux valgus randomly into two groups using a closed-envelope system. One group (S) had fixation by a screw followed by early weight-bearing in a soft shoe. There were two men and 13 women with a mean age of 43.7 years (19 to 68; SD, 13.7). The other group (V) had stabilisation by a No. 1 vicryl suture followed by non-weight-bearing in a plaster boot for six weeks before weight-bearing was allowed. There were three men and 12 women with a mean age of 44.3 years $(21$ to 67 ; SD, 12.4).

All procedures were identical, except for the method of fixation, and were carried out by the same surgeon (JDFC).

The patients were assessed before operation and at six weeks, three months, six months and one year. Clinical evaluation was carried out by the forefoot scoring system (FFSS) of the Mayo clinic. ${ }^{4}$ The range of movement (ROM) at the metatarsophalangeal (MTP) joint was also assessed. By use of a questionnaire, patients were asked how satisfied they were with the appearance after surgery and at what stage they had been able to return to specific activities (Table I). Radiological examination consisted of standard anteroposterior weight-bearing films plus a $60^{\circ}$ internal oblique view to assess displacement of the osteotomy (Fig. 1). 
Table I. Details of the assessment questionnaire

\begin{tabular}{|c|c|}
\hline & Score \\
\hline $\begin{array}{l}\text { Patient satisfaction with appearance } \\
\text { Excellent } \\
\text { Good } \\
\text { Fair } \\
\text { Poor }\end{array}$ & \\
\hline Return to housework: & weeks \\
\hline Return to full-time employment: & weeks \\
\hline $\begin{array}{l}\text { Clinical assessment (FFSS) } \\
\text { 1. Pain site } \\
\text { Exostosis } \\
\text { 1st MTP joint } \\
\text { Metatarsal heads }\end{array}$ & $\begin{array}{l}\mathrm{Y} / \mathrm{N} \\
\mathrm{Y} / \mathrm{N} \\
\mathrm{Y} / \mathrm{N}\end{array}$ \\
\hline $\begin{array}{l}\text { 2. Pain } \\
\text { None } \\
\text { Mild - occasional but minimal } \\
\text { Moderate - significant, daily } \\
\text { Severe - almost always present }\end{array}$ & $\begin{array}{r}30 \\
20 \\
10 \\
0\end{array}$ \\
\hline $\begin{array}{l}\text { 3. Functional restriction } \\
\text { None } \\
\text { Mild: some limitations } \\
\text { Moderate: no sport activities } \\
\text { Severe: major limitation }\end{array}$ & $\begin{array}{r}15 \\
10 \\
5 \\
0\end{array}$ \\
\hline $\begin{array}{l}\text { 4. Footwear restriction } \\
\text { None, mild: some stylish shoes } \\
\text { Moderate: no stylish shoes } \\
\text { Severe: modified shoes }\end{array}$ & $\begin{array}{r}10 \\
5 \\
0\end{array}$ \\
\hline $\begin{array}{l}\text { 5. Tender, painful callus } \\
\text { None } \\
\text { Present }\end{array}$ & $\begin{array}{r}10 \\
0\end{array}$ \\
\hline $\begin{array}{l}\text { 6. Alignment, objectionable } \\
\text { None, or noticeable but acceptable } \\
\text { Objectionable alignment }\end{array}$ & $\begin{array}{l}5 \\
0\end{array}$ \\
\hline $\begin{array}{l}\text { 7. Stiffness } \\
\text { None } \\
\text { Present }\end{array}$ & $\begin{array}{l}5 \\
0\end{array}$ \\
\hline $\begin{array}{l}\text { Total score } \\
\text { FFSS Result (Excellent/Good/Fair/Poor) }\end{array}$ & \\
\hline $\begin{array}{l}\text { ROM MTP Joint } \\
\text { Dorsiflexion }(\text { norm = 75) } \\
\text { Active } \\
\text { Passive } \\
\text { Plantar flexion }(\text { norm }=45) \\
\text { Active } \\
\text { Passive }\end{array}$ & \\
\hline
\end{tabular}

Statistical significance was evaluated by the Student's $t$ test and the level of significance was set at $p<0.05$. A prospective calculation of sample size was undertaken. With 15 patients in each group, a difference between the two groups of 1.1 standard deviations would be detected as significant at the $5 \%$ level with a power of $80 \%$.

\section{Results}

All 30 patients were available for clinical and radiological follow-up at six weeks, three months, six months and one year (Table II). There was no statistically significant difference between the two groups when assessed before operation.

Patient satisfaction and convalescence. At six weeks, good or excellent results were reported by $93 \%$ of those in group $\mathrm{S}$ and $73 \%$ of patients in group V. The difference was not significant. From three months onwards, all patients in both groups reported either good or excellent results. The mean time before returning to light housework was 2.9 weeks (95\% CI, 2.4 to 3.4) in group S and 5.7 weeks (95\% $\mathrm{CI}, 4.9$ to 6.5$)$ in group $\mathrm{V}(\mathrm{p}<0.001)$. The mean time before returning to full employment or normal housework or gardening activities was 4.9 weeks (95\% CI, 4.2 to 5.6) in group $\mathrm{S}$ and 8.7 weeks (95\% CI, 7.7 to 9.7) in group V $(\mathrm{p}<0.001)$.

Functional assessment. There was no difference in the pain scores between the two groups at any stage of follow-up. The mean functional scores were significantly different at six weeks $(p=0.025)$ and at three months $(p=0.006)$. There was also increased stiffness at the MTP joint in group $\mathrm{V}$ when compared with group $\mathrm{S}$ at six weeks $(\mathrm{p}=0.048)$ and at three months $(\mathrm{p}=0.032)$. No difference in either the functional scores or joint stiffness could be shown beyond three months. At one year there was no difference in the overall active or passive movement at the MTP joint.

The mean total FFSS for groups $\mathrm{S}$ and V, respectively, was 55.3 and 43.0 at six weeks $(\mathrm{p}=0.04)$ and 65.7 and 58.0 at three months $(\mathrm{p}=0.02)$. No statistically significant difference in total scores could be demonstrated between the two groups beyond three months.

Radiological assessment. The results of the radiological assessments are shown in Table III. Preoperatively, group S patients had a mean hallux valgus angle of $26.5^{\circ}(\mathrm{SD}, 3.8)$ and a mean angle of metatarsus primus varus of $14.0^{\circ}$ (SD, 2.4). Group-V patients had a mean hallux valgus angle of $29.8^{\circ}(\mathrm{SD}, 5.5)$ and a mean angle of metatarsus primus varus of $14.1^{\circ}(\mathrm{SD}, 1.4)$.

Six weeks after operation, the mean hallux valgus angle was $10.4^{\circ}(\mathrm{SD}, 3.5)$ in group $\mathrm{S}$ and $9.0^{\circ}(\mathrm{SD}, 6.1)$ in group $\mathrm{V}$. The mean intermetatarsal angle was $7.7^{\circ}$ in both groups (SD, 2.9 in group $\mathrm{S}$ and SD, 1.8 in group V). The mean shortening of the first metatarsal at six weeks was $4.3 \mathrm{~mm}$ ( $\mathrm{SD}, 2.2)$ in group $\mathrm{V}$ and $3.3 \mathrm{~mm}(\mathrm{sD}, 4.1)$ in group $\mathrm{S}$, with no statistically significant difference between the two.

No displacement of the osteotomy was seen in either group and no significant change was shown in the hallux valgus or intermetatarsal angles from six weeks to one year after operation.

Complications. Two patients in group S (13\%) had developed pain at the site of the screw head when seen after six months. Both screws were removed under local anaesthesia after which the patients were free from symptoms. Three patients $(10 \%)$, one in group $\mathrm{V}$ and two in group $\mathrm{S}$, had inflammation around the wound and were given a twoweek course of antibiotics. All three suspected superficial wound infections settled quickly and remained quiescent. There was no deep infection.

\section{Discussion}

Mitchell's osteotomy is a popular procedure for the correction of mild to moderate hallux valgus. Various operative 


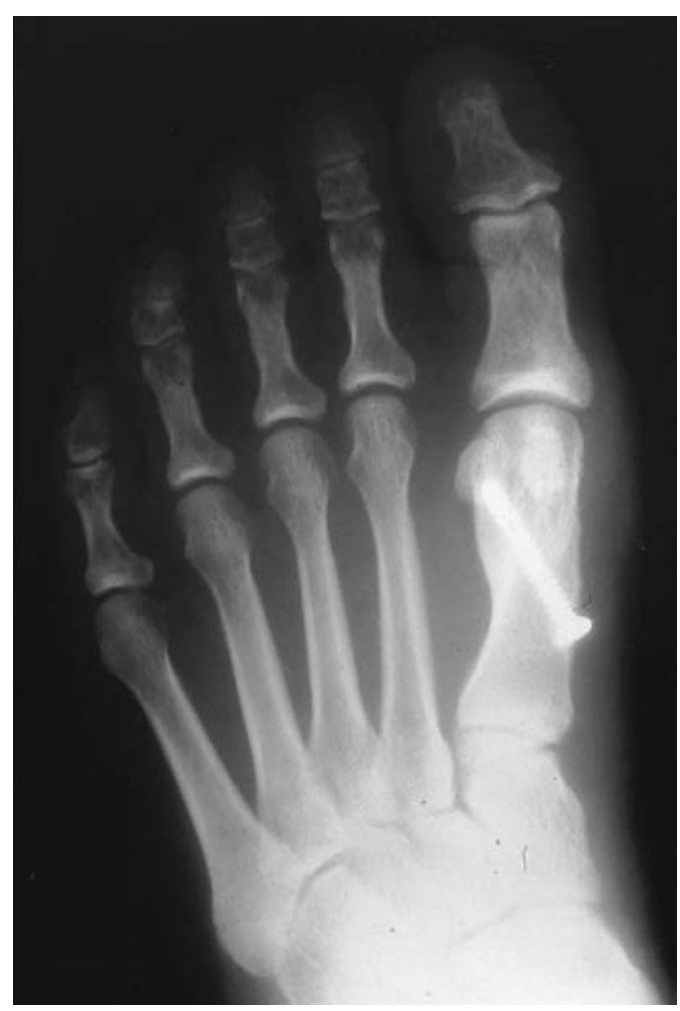

Fig. 1a

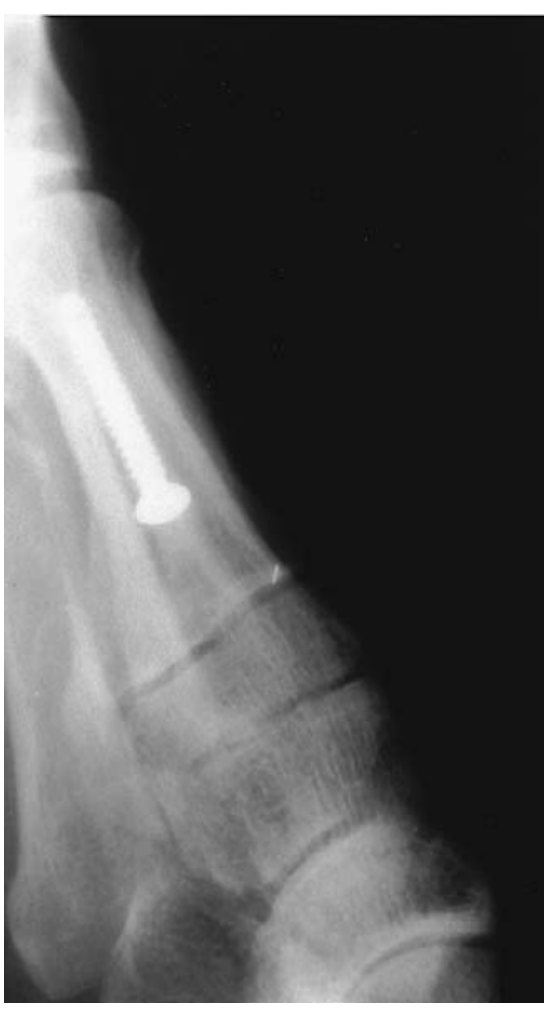

Fig. 1b
Anteroposterior (a) and lateral (b) weight-bearing radiographs after one year showing union of the osteotomy and internal fixation by a screw.
Table II. The results (mean \pm SD) of surgery for the 15 patients in group $\mathrm{V}$ (vicryl-fixation) and the 15 in group $\mathrm{S}$ (screw fixation)

\begin{tabular}{|c|c|c|c|}
\hline Outcome variable & $\begin{array}{l}\text { Vicryl } \\
\text { fixation }\end{array}$ & $\begin{array}{l}\text { Screw } \\
\text { fixation }\end{array}$ & p value \\
\hline Return to social activities in weeks & $5.7 \pm 1.67$ & $2.9 \pm 0.88$ & $<0.001$ \\
\hline Return to work in weeks & $8.7 \pm 1.91$ & $4.9 \pm 1.46$ & $<0.001$ \\
\hline \multicolumn{4}{|l|}{$\begin{array}{l}\text { Pain score } 0 \text { to } 30 \\
(30=\text { pain free })\end{array}$} \\
\hline 6 weeks & $18.7 \pm 9.9$ & $21.3 \pm 5.2$ & 0.363 \\
\hline 3 months & $25.3 \pm 5.2$ & $25.3 \pm 6.4$ & - \\
\hline 6 months & $24.0 \pm 6.3$ & $26.7 \pm 4.9$ & 0.207 \\
\hline 1 year & $26.7 \pm 4.9$ & $26.7 \pm 4.9$ & - \\
\hline \multicolumn{4}{|l|}{$\begin{array}{l}\text { MTP stiffness } 0 \text { to } 5 \\
(5=\text { no stiffness })\end{array}$} \\
\hline 6 weeks & $2.7 \pm 2.6$ & $4.3 \pm 1.8$ & 0.048 \\
\hline 3 months & $3.7 \pm 2.3$ & $5.0 \pm 0.0$ & 0.032 \\
\hline 6 months & $5.0 \pm 0.0$ & $5.0 \pm 0.0$ & - \\
\hline 1 year & $5.0 \pm 0.0$ & $5.0 \pm 0.0$ & - \\
\hline \multicolumn{4}{|l|}{$\begin{array}{l}\text { Function score } 0 \text { to } 15 \\
(15=\text { normal function })\end{array}$} \\
\hline 6 weeks & $4.7 \pm 4.4$ & $8.0 \pm 3.2$ & 0.025 \\
\hline 3 months & $7.7 \pm 3.7$ & $11.3 \pm 3.0$ & 0.006 \\
\hline 6 months & $12.7 \pm 2.6$ & $13.0 \pm 3.2$ & 0.754 \\
\hline 1 year & $13.9 \pm 2.3$ & $15.0 \pm 1.8$ & 0.245 \\
\hline \multicolumn{4}{|l|}{ Total FFSS $(0 \text { to } 75)^{*}$} \\
\hline 6 weeks & $43.0 \pm 19.5$ & $55.3 \pm 9.5$ & 0.036 \\
\hline 3 months & $58.0 \pm 9.2$ & $65.7 \pm 8.4$ & 0.024 \\
\hline 6 months & $66.0 \pm 9.1$ & $68.0 \pm 8.2$ & 0.532 \\
\hline 1 year & $68.9 \pm 7.8$ & $69.0 \pm 6.6$ & 0.952 \\
\hline
\end{tabular}

* 70 to 75 , excellent; 60 to 70 , good; 50 to 60 , fair; $<50$, poor

techniques have been described in an attempt to reduce the period of immobilisation required after stabilisation of the osteotomy with a suture, ${ }^{5-7}$ but there are few comparative
Table III. Mean ( \pm SD) radiological assessment for the 15 patients in group V (vicryl-fixation) and the 15 in group $\mathrm{S}$ (screw fixation)

\begin{tabular}{lrrr}
\hline Outcome variable & $\begin{array}{l}\text { Vicryl } \\
\text { fixation }\end{array}$ & \multicolumn{1}{l}{$\begin{array}{l}\text { Screw } \\
\text { fixation }\end{array}$} & p value \\
\hline Hallux valgus angle in degrees & & & \\
$\quad$ Preoperation & $29.8 \pm 5.5$ & $26.5 \pm 3.8$ & 0.07 \\
6 weeks & $9.0 \pm 6.1$ & $10.4 \pm 3.5$ & 0.45 \\
3 months & $9.8 \pm 5.3$ & $10.5 \pm 3.5$ & 0.69 \\
6 months & $10.9 \pm 6.0$ & $11.2 \pm 3.5$ & 0.85 \\
1 year & $10.8 \pm 5.9$ & $12.0 \pm 3.8$ & 0.73 \\
Intermetatarsal angle in degrees & & & \\
$\quad$ Preoperation & $14.1 \pm 1.4$ & $14.0 \pm 2.4$ & 0.21 \\
6 weeks & $7.7 \pm 1.8$ & $7.7 \pm 2.9$ & - \\
3 months & $8.1 \pm 1.9$ & $8.9 \pm 3.8$ & 0.53 \\
6 months & $8.4 \pm 2.1$ & $9.5 \pm 3.6$ & 0.33 \\
1 year & $9.1 \pm 2.3$ & $10.7 \pm 3.6$ & 0.45 \\
Shortening in mm & & & \\
$\quad 6$ weeks & $4.3 \pm 2.2$ & $3.3 \pm 4.1$ & 0.13 \\
3 months & $5.0 \pm 2.6$ & $3.9 \pm 3.5$ & 0.10 \\
6 months & $5.2 \pm 2.6$ & $4.4 \pm 4.3$ & 0.14 \\
1 year & $5.5 \pm 2.3$ & $4.4 \pm 3.4$ & 0.24 \\
\hline
\end{tabular}

clinical studies which investigate different methods of fixation.

Our study was supported by biomechanical data and has shown that fixation of the osteotomy by a screw provides stability, and is strong enough to allow early mobilisation. We have demonstrated significant reduction in the time taken to return to social and working activities. All our patients were satisfied with the result and all the osteotomies united.

Stiffness at the MTP joint is recognised as a common problem after distal metatarsal osteotomy and correlates well 
with the result of surgery. ${ }^{2,8}$ It has been avoided in the group with fixation by a screw, presumably because of the early encouragement to mobilise. There were no significant differences in the radiological or clinical measurements between the two groups of patients three months after operation.

The need for removal of the screw because of localised pain and tenderness may have been due to inadequate counter-sinking of the head. Fixation of the Mitchell's osteotomy by a screw, combined with early mobilisation, relies on good quality of bone for secure fixation. This procedure is suitable for young patients who wish to mobilise early and return to social activities or work soon after surgery. The patients should be informed that up to $15 \%$ of screws may need to be removed under local anaesthesia by six months.

The authors would like to thank Caroline Doré, BSc, Senior Statistician, Department of Medical Statistics and Evaluation, Imperial College School of Medicine for the statistical analysis of our results.

No benefits in any form have been received or will be received from a commercial party related directly or indirectly to the subject of this article.

\section{References}

1. Hawkins FB, Mitchell CL, Hedrick DW. Correction of hallux valgus by metatarsal osteotomy. J Bone Joint Surg 1945;27:387-94.

2. Mitchell CL, Fleming JL, Allen R, Glenney C, Sanford GA. Osteotomy-bunionectomy for hallux valgus. J Bone Joint Surg [Am] 1958; 40-A:41-60.

3. Calder JD, Hollingdale JP. Measurement of strength and stability of suture versus AO screw fixation of Mitchell's osteotomy: a cadaveric study. The Foot 1997;7:220-3.

4. Kitaoka HB, Alexander IJ, Adelaar RS, et al. Clinical rating systems for the ankle-hindfoot, midfoot, hallux, and lesser toes. Foot Ankle Int 1994;15:349-53.

5. Briggs TWR, Smith P, McAuliffe TB. Mitchell's osteotomy using internal fixation and early mobilisation. J Bone Joint Surg [Br] 1992; 74-B:137-9.

6. Prior TD, Grace DL, MacLean JB, et al. Correction of hallux abductus valgus by Mitchell's metatarsal osteotomy: comparing standard fixation methods with absorbable polydioxanone pins. The Foot $1997 ; 7: 121-5$

7. Bonner AC. Rigid internal fixation of the Mitchell-Hawkins osteotomy/bunionectomy with the Herbert bone screw. J Foot Surg 1986; 25:390-3.

8. Klosok JK, Pring DJ, Jessop JH, Maffulli N. Chevron or Wilson metatarsal osteotomy for hallux valgus: a prospective randomised trial. J Bone Joint Surg [Br] 1993;75-B:825-9. 